tion. It would not be concerned with specific proposals for producing and using desalted water in Britain. The Water Resources Board, which under the Water Resources Act, 1963, had a statutory interest in desalination, was to be invited to nominate a representative to the Advisory Committee, on which the Water Research Association was already represented. This Association was at present engaged in a three-year assessment of the economic and technical feasibility of applying desalination to the British water supply. An interim report on this investigation, begun in October 1964, was expected later this year.

The Advisory Committee would facilitate co-ordination of the activities of the Authority and of their commercial collaborators in developing desalinating techniques for exploitation both at home and abroad. British industry has been mainly responsible for the methods of desalination now in use and for the design and manufacture of most of the desalination plants operating in the world to-day. The Government intended to do everything possible to maintain Britain's leading position in this important field and to ensure that Britain took an appropriate share of what is likely to be a rapidly increasing export market.

\section{The Radio and Space Research Station}

THe name of the Radio Research Station, an establishment of the Science Research Council, has been changed to the Radio and Space Research Station. It was decided in 1959 that half the total effort of the Station should be devoted to space research. The main work of the Station continues to be at Ditton Park, Bucks. In addition, the Station is responsible for the operation at Winkfield, Berks, of a minitrack installation for tracking and receiving telemetry from satellites. It also operates small research stations at Port Stanley in the Falkland Islands, at Singapore and at Lerwick, Shetland Islands. The radio telescope under construction at Chilbolton, Hants, is expected to come into operation in 1966 and will be used. for research into radio wave propagation and in space research.

\section{International Union of Biological Sciences: Section on Biological Oceanography}

Ar the fifteenth General Assembly of the International Union of Biological Sciences, held in Prague in July 1964, a new Section on Biological Oceanography was created within the Union. The recent growth of oceanography and the participation of countries all over the world have led to the need for improved planning and co-ordination of its international activities, but the diversity of scientific disciplines involved inevitably makes it necessary for the organizing bodies to cover a very wide field. It has thus become a matter of great importance to ensure that adequate backing and guidance are provided by the scientists in each discipline. In physical oceanography this support is available through the Intemational Association of Physical Oceanography (an association within the International Union of Geodesy and Geophysics), but in biological oceanography there has been no adequate counterpart. Only the regional fisheries organizations have been in a position to make any representation of biological matters.

Biological oceanography, contrary to the generally widespread opinion, is a comparatively neglected subject. It is true that biologists have examined marine plants and animals for a very long time, but these investigations have very largely been of organisms as component parts of the plant and animal kingdoms. The study of the living communities as an integral part of the sea has by comparison received relatively little attention, and yet it is information of this nature which we must acquire before we can hope to understand the cycle of life in the sea and its spatial and temporal variations. A small committee with Prof. E. Steemann Nielsen (Denmark) as chairman and R. I. Currie (Great Britain) as secretary has been set up to arrange the first meeting of the section which it is intended to hold during the second International Oceanographical Congress in Leningrad in 1966.

\section{Ore Dressing Investigations in Australia}

Ore dressing investigations performed in the Ore Dressing Laboratory of the University of Melbourne are carried out under the joint control of the Commonwealth Scientific and Industrial Research Organization and the Mining Department of the University. The annual report of the Laboratory for 1963-64 discloses that, following extended consultations with representatives of the Australian Mineral Industry Research Association and of some of its associated mining and mineral companies, two new basic long-term research projects have recently been initiated (Pp. 10. Melbourne: Commonwealth Scientific and Industrial Research Organization, 1964). One is the chemistry of flotation pulps; the other, ore grindability. Regarding the former, the basis of the problem is to extend our knowledge of the chemistry of oro-pulp reactions particularly with regard to their influence on the flotation of sulphide minerals. The objectives of the ore grindability project are to obtain reliable and extensive grindability data for a wide variety of Australian ores, also to investigate the precision and reproducibility of the Allis-Chalmers grindability test, and of possible modifications of it, with emphasis on the reliability of this form of testing in predicting plant performance. Other collateral research projects described in this report include gold recovery from complex gold sulphide concentrates; contamination of sulphide copper concentrates by nickel from grinding balls; gravity concentration: studies of a gapped launder under various operating conditions; the movement of solid spheres, immersed in water, in a tube, that is, methods for determining ball and water velocity, so as to provide a key to ball behaviour when movement consists of translation, rotation or oscillation or combinations of these phases. Progress has also been made in high-tension separation, in investigating the pattern of discharge from the ionizing electrode of a laboratory high-tension separator. In the section devoted to chemical analysis, work has been carried out on determination of tin by the cathode-ray polarograph; it was previously observed that tungsten gave a distinct peak at $0.2 \mathrm{~V}$ more negative than tin; it is now shown that a linear relationship exists between peak height and concentration of tungsten in a 5-M hydrochloric acid solution. Other chemical studies have included a modification of the Gutzeit method for arsenic and some electrolytic experiments on cassiterite. The report also gives details of special investigations carried out directly for the industry, for example, silica products, copper and gold ores.

\section{Bio-Probe}

Bro-Prose is holding an exhibition demonstrating a mobile unit, and an example of a fixed summer camp, during May 22-24 at Dutchlands Farm, Great Missenden, Bucks. Bio-Probe is being constituted as a non-profitmaking company limited by guarantee and administered by a council of directors. Its objects are: to improve the facilities available for education and training in the field sciences; to encourage among the public an increased awareness of natural history and the need for conservation; to provide a training area in the United Kingdom for scientists going overseas; to provide workshop facilities, and pools of well-serviced equipment. It will sponsor overseas research and equip and organize research teams. Equipment will be made available in countries overseas for the use of research teams from universities and other organizations. The Bio-Probe organization will include a film unit, a film library and a reprint service of field 